\title{
0 limite máximo da medida de segurança
}

\author{
The maximum limit of the criminal compulsory commitment
}

Rafael de Souza Borelli ${ }^{1}$

\begin{abstract}
Resumo
0 Direito foi o meio encontrado para ordenar as relações sociais. No interior do Direito o ramo do Direito penal é o responsável pelas sanções mais incisivas e pela defesa dos valores sociais mais caros. A ideia de direito penal e de sanção penal inicialmente tinha ligação com a 'retribuição' ao criminoso do mal que ele havia causado. Posteriormente, percebeu-se que a visão retributiva era insuficiente para realizar um dos objetivos do encarceramento, o qual era a expiação do criminoso, 0 arrependimento. Por isso, passou-se a aplicar a pena com um viés também preventivo, ou seja, a pena servia como meio de intimidação dos criminosos em potencial, e nao só como meio retributivo aos criminosos efetivos. Contudo, esta nova visão passou ao largo de um problema concreto, vez que certos criminosos nao possuíam capacidade de autodeterminação, ou seja, ao momento dos fatos eles não possuíam o necessário discernimento acerca do caráter ilícito do fato. Disso extraiu-se a necessidade de divisão da sanção penal em duas: a pena e a medida de segurança. 0 foco deste estudo é a análise da natureza jurídica, espécies e dos pressupostos para aplicação da medida de segurança. Após isto, ingressa-se na problemática específica do ensaio, com estudo acerca do limite máximo de duração da medida de segurança, vez que não existe consenso na literatura jurídica acerca do tema, existindo ampla gama de posições, a saber: a medida de segurança não tem limite máximo; a medida de segurança tem o limite de trinta anos, da mesma forma que a pena privativa de liberdade; a medida de segurança tem o limite máximo igual ao máximo da pena em abstrato daquele delito; entre outras. Por fim, verifica-se que a solução ao problema apresentado passa pela aplicação da regra da proporcionalidade, criada pelo jurista tedesco Robert Alexy e que será usada como substrato à pesquisa.
\end{abstract}

Palavras-chave: Medida de segurança. Limite máximo de duração. Regra da proporcionalidade.

Abstract
The Law has been the main way of creating a certain order in society. Crime Law is
law's branch responsible for the harshest sanctions and for the defense of the most
important social values. The notions of Crime Law and of Criminal Sanction were

${ }^{1}$ Graduado em Direito pela Universidade Estadual de Londrina/PR. Especialista em Direito Penal pela Fundação Escola do Ministério Público do Estado do Paraná. Advogado.

Revista de Direito Público, LondRina, V. 6, N. 3, P. 53-77, OUT/DEZ 2011. 
initially connected with the idea of 'retribution', or, in other words, 'an eye for an eye'. As time passed, it became obvious that the whole idea of retribution was insufficient to fulfill one of the goals of imprisonment: repent. Because of that, the criminal sanction began to be seen with a preventive view, in other words, the prison term served a two-edged objective: intimidation of the potential criminals, and retribution to the effective criminals. However, this new approach ignored a concrete problem: the issue of mental capacity. That is an important issue, as some criminals lack the mental health and may present a danger to self or others. In relation to this issue was born the necessity of the division of criminal sanction in two: the prison term and the compulsory (mandatory commitment). The initial scope of this essay is to analyze the nature, the species and the requisites of the compulsory commitment in crime law. Afterwards, we enter on the specific problematic: the maximum duration o the criminal compulsory commitment. The matter is confrontational, as the juridical literature has a large gamma of standings. At last, the answer is found by application of the proportionality rule, as created by the german author Robert Alexy.

Keywords: Compulsory commitment in crime law; Maximum duration.; Reasonableness.

\section{Introdução}

O presente trabalho buscará, de maneira não exauriente, elucidar a problemática da duração máxima das medidas de segurança, com análise das posições tanto jurisprudenciais como doutrinárias, verificando qual a mais correta com base nos princípios vigentes na Constituição Federal.

Para tanto, iniciar-se-á o estudo com breve análise do Direito, mais especificamente do Direito Penal, seus objetivos históricos e atuais. Em seguida, anotar-se-á a evolução teórica do Direito Penal, ultimando-se esta com a divisão da sanção penal em duas, a pena e a medida de segurança.

Após breve discurso sobre a pena, adentrar-se-á, de maneira mais aprofundada, no estudo do instituto penal da medida de segurança, com sua conceituação, classificação e pressupostos de aplicação.

Consectariamente trazem-se a lume alguns dos princípios constitucionais que regem a medida de segurança, discorrendo-se sobre seus contornos conceituais, características e aplicabilidade, tudo com o escopo de esclarecer ao leitor os elementos cardinais que orientam a referida instituição.

Revista de Direito Público, LondRINA, V. 6, N. 3, P. 53-77, OUT/DEZ. 2011. 
0 estudo em tela tem como ponto nevrálgico o limite máximo de duração da medida de segurança. É cediço que hodiernamente existem três correntes divergentes acerca deste tema, esposadas pelos mais variados órgãos jurisdicionais e autores penais.

À luz destas correntes, com a aplicação dos princípios constitucionais antes mencionados, buscar-se-á solução satisfatória ao problema apresentado, com sistematização teórica e prática da solução criada à problemática.

\section{Sanção penal}

O Direito corresponde à exigência essencial e indeclinável de uma convivência ordenada, vez que nenhuma sociedade poderia subsistir sem um mínimo de ordem, direção e solidariedade (REALE, 2005, p. 2). Portanto, é de se entender que o Direito nas sociedades atuais funciona como meio que permite a coexistência pacífica dos cidadãos. Não é exagero admitir que sem o Direito chegar-se-ia muito perto da barbárie.

Dentro do Direito, o ramo que nos interessa neste estudo é o Direito Penal. É importante salientar que em toda convivência social existem transgressões, ilícitos por parte dos cidadãos. Com efeito, toda transgressão do Direito constitui-se num ilícito que não pode ser tolerado, visto que sem o temor da sanção os atores sociais transgrediriam o contrato social em que vivem.

Não se deve perder de vista, porém, que não são todos os ilícitos jurídicos que tem importância para o Direito Penal. 0 ilícito penal é apenas aquele que contraria os bens mais importantes da vida social, quando a lesão aos interesses da sociedade assume tal proporção que os demais meios de controle mostram-se ineficientes, tornando assim necessária a utilização do Direito Penal como meio de controle social (BITENCOURT, 2008, p. 1.)

Tal construção não é realizada à toa. Isso porque o ramo penal do Direito é o único que tem como possibilidade de retribuição ao transgressor a privação de sua liberdade. A 'pena' é a retribuição que o Estado impõe aos criminosos, os que violaram a norma penal. Malum propter malum, o mal se retribui com o mal, essa era a concepção tradicional do sistema penal (BRUNO, 2009, p. 3).

Revista de Direito Púbuco, LondRINA, V. 6, N. 3, P. 53-77, OUT/DEZ. 2011. 
A ideia da retribuição ao delinquente baseava-se no entendimento de que o Estado deveria responder ao mal injusto praticado de acordo com a gravidade do fato, o bem ofendido e a grandeza de sua culpabilidade (BRUNO, 2009, p. 4).

Entretanto, essa ideia, com o passar dos séculos, foi tornando-se obsoleta. Através da pena esperava-se a expiação do criminoso, o arrependimento, com posterior retorno deste ao convívio social, conseqüência que não foi atingida. Cada vez mais, aqueles que passavam tempo encarcerados retornavam ao convívio social apenas para novamente violarem o contrato social (BITENCOURT, 2008, p. 118).

Devido à falência do sistema meramente retributivo, passou-se a utilizar do sistema preventivo, onde havia uma finalidade dual, qual seja, de retribuir, mas também de prevenir a criminalidade. Isso era feito com a ideia da ressocialização gradual do condenado (BECCARIA, 2002, passim)

Contudo, mesmo este sistema, mais humano, possuía suas falhas. Tratavam-se todos que cometiam delitos da mesma maneira, com retribuição e prevenção. Isso ignorava o fato de que certos transgressores da lei penal não podiam se autodeterminar perfeitamente.

Sistema dualista

Evoluindo em relação ao sistema monista anterior, o sistema dualista (SANTOS, 1995), com um viés mais humano, buscou a solução do problema acima apontado com a divisão do gênero sanção penal em duas espécies: a pena e a medida de segurança (CALDEIRA, 2009.)

Pena

A pena é a sanção aflitiva imposta pelo Estado, mediante ação penal, ao autor de uma infração (penal) como retribuição de seu ato ilícito, cujo fim é evitar novos delitos (JESUS, 2006, p. 519).

Revista de Direito Público, LondRINA, V. 6, N. 3, P. 53-77, OUT/DEZ. 2011. 
Como frisado acima, a pena tem caráter de prevenção geral e especial. 0 destinatário da prevenção é o meio coletivo, sendo o da especial o próprio criminoso. Inclusive, o Código Penal adota esta ideia no texto normativo de seu artigo 59. ${ }^{2}$

A prevenção geral exercida pela pena deriva da intimidação psicológica relacionada com a ameaça da sanção ao ilícito penal. A prevenção especial, por sua vez promove, para evitar a reincidência, a correção individual do criminoso. (BRUNO, 2009, p. 21).

No ordenamento jurídico brasileiro atual, existem três tipos de pena: privativa de liberdade, restritiva de direitos e de multa.

Todavia, sob pena de exaurir o pequeno espaço com tão interessante tema, passase à análise propriamente dita do objeto do presente artigo, a medida de segurança.

\section{Medida de Segurança}

\section{Contornos conceituais}

A medida de segurança, no universo jurídico, situa-se como espécie do gênero sanção penal. Reale Ferrari entende que a mesma constitui-se numa providência do poder político que impede que determinada pessoa, ao cometer um ilícito penal revelando periculosidade latente volte ao convívio social sem um tratamento médico adequado (FERRARI, 2001, p. 15).

No mesmo tom, Ribeiro (1998, p. 9) entende a medida de segurança como instrumento utilizado pelo Direito Penal para a defesa da sociedade contra o potencial ofensivo à ordem jurídica inerente aos indivíduos considerados 'perigosos' ao convívio social. Para 0 autor, a medida de segurança tem como fim a remoção da periculosidade do indivíduo que representa risco, tanto com a remoção dele do meio social, como do tratamento dado ao mesmo.

Como se vê, a medida de segurança, diferentemente da pena, não tem como objeto a retribuição e sim a proteção, tanto do meio social, como do doente mental.

\footnotetext{
${ }^{2} \mathrm{O}$ juiz, atendendo à culpabilidade, aos antecedentes, à conduta social, à personalidade do agente, aos motivos, às circunstâncias e conseqüências do crime, bem como ao comportamento da vítima, estabelecerá, conforme seja necessário e suficiente para reprovação e prevenção do crime:
} 
Discrepâncias conceituais entre pena e medida de segurança

$\mathrm{Na}$ esteira do tópico anterior, vê-se que a medida de segurança e a pena, apesar de ambas serem espécies do gênero sanção penal tem características e objetos sobremaneira diferentes.

Em resumo, existem algumas discrepâncias entre os dois institutos. A pena tem como fundamento a culpabilidade, enquanto a medida de segurança funda-se na periculosidade. A pena é fixa e proporcional à infração, enquanto a medida de segurança, para a doutrina tradicional, caracteriza-se pela indeterminação temporal (PANCHERI, 1997).

Disso se depreende as vitais diferenças entre a pena e a medida de segurança. Isso superado, imperioso um estudo sobre a história das medidas de segurança para que se avance, posteriormente, no deslinde da questão aqui apresentada a estudo.

\section{Breve escorço histórico}

De acordo com Fragoso (1985, p. 403), infere-se que a origem do instituto jurídico das medidas de seguranças surgiu no Direito Romano. Segundo o autor, os romanos visavam retirar do convívio societário os chamados furiosi. Ferrari também explica a origem romana do instituto, narrando que, de início, os furiosi eram os menores infratores e os ébrios habituais, com posterior incremento à lista dos doentes mentais (FERRARI, 2001. p. 16).

Ribeiro (1998, p. 10), em profundo estudo sobre a matéria descreve que o Código Penal Francês de 1810 [período napoleônico] ordenava a segregação indefinida dos chamados 'vagabundos'. De acordo com o penalista, ainda em França, em 1885 passou a haver uma previsão legal de uma 'pena complementar' para os polirreincidentes, que se entendiam como irrecuperáveis. Importante salientar que estes marcos legais franceses foram adotados por boa parte das nações europeias, o que acabou por influenciar fortemente a legislação brasileira daquele tempo.

No Brasil, o Código Criminal do Império previa que os 'loucos' que houvessem cometido delitos deveriam ou recolher-se a manicômios ou serem entregues às suas famílias, dependendo do caso concreto. Disposições similares foram elencadas no Código Penal da 1ª República (1890). M ais modernamente, 0 atual Código, em sua redação original, 
adotou a nomenclatura medida de segurança, e previu que diversas categorias de indivíduos 'perigosos' casas de custódia e tratamento, colônias de trabalho ou até de exílio (RIBEIRO, 1998, p. 10).

Com o Código Penal de 1940, sistematizou-se de maneira mais técnica e satisfatória 0 instituto da medida de segurança em nosso país.

À época, a medida de segurança era aplicada com a ocorrência de dois requisitos cumulados, quais sejam:

a) a prática de fato criminoso;

b) a periculosidade do agente. ${ }^{4}$

A despeito disso, aquele Código dispunha acerca de exceções aos mencionados requisitos, com a possibilidade da decretação da medida em caso de extrema periculosidade social. ${ }^{5}$

Tratava-se de um arbítrio estatal. Um indivíduo que nunca transgredira a legislação penal poderia ser trancafiado por tempo indeterminado caso fosse considerado perigoso.

Antes de adentrar-se a atual sistemática adotada na legislação pátria, é de se verificar os sistemas de responsabilização do doente mental.

Sistemas duplo binário e vicariante

O sistema do duplo binário foi o adotado originalmente no Código Penal de 1940. 0 citado sistema fazia com que o condenado inimputável além de cumprir pena, tinha de posteriormente ser submetido à medida de segurança, ocorrendo verdadeiro bis in idem (BITENCOURT, 2008. p. 698).

Sobre o sistema Fragoso (1984) disserta:

Ao sistema do duplo binário se chega partindo-se da concepção clássica da pena retributiva e expiatória e de suas manifestas insuficiências. Formula-se na doutrina a teoria das medidas de segurança distinguindo-se da pena porque esta se funda na culpabilidade do agente, e por ela se mede, aplicando-se aos imputáveis, ao passo

\footnotetext{
${ }^{3}$ Inimputáveis e semi-imputáveis por enfermidade mental, ébrios habituais condenados por crime em que estavam embriagados, reincidentes em crimes dolosos ou condenados por crime de quadrilha.

${ }_{5}^{4}$ Artigo 76 daquele diploma legislativo.

${ }^{5}$ Art. 76, Parágrafo único. A medida de segurança é também aplicável nos casos dos arts. 14 e 27, se ocorre a condição do n. II [periculosidade doa gente].

ReVISTA De DiReITo Púbuico, LondRINA, V. 6, N. 3, P. 53-77, OUT/DEZ. 2011. 
que as medidas se fundam na periculosidade, e por ela se medem, aplicando-se tanto aos imputáveis como aos inimputáveis. A pena, em conseqüência, se funda na justiça, como justa retribuição, ao passo que a medida de segurança se funda na utilidade. A pena é sanção e se aplica por fato certo, o crime praticado, ao passo que a medida de segurança não é sanção e se aplica por fato provável, a repetição de novos crimes. A pena é medida aflitiva, ao passo que a medida de segurança é tratamento, tendo natureza assistencial, medicinal ou pedagógica. 0 caráter aflitivo que esta última apresenta não é um fim pretendido, mas meio indispensável à sua execução finalística. A pena visa à prevenção geral e especial, ao passo que a medida de segurança visa apenas à prevenção especial, consistente na recuperação social ou na neutralização do criminoso.

0 mesmo autor critica severamente a escolha legislativa feita à época, visto que a experiência com o sistema duplo binário havia falido em todo o mundo.

$\mathrm{Na}$ verdade, o sistema do duplo binário era utilizado para segregação de determinados indesejados do convívio social, vez que o criminoso, além de cumprir uma pena por tempo determinado, era em seguida ao cumprimento da pena submetido, por uma duração indeterminada, à medida de segurança (D'URSO, 1993).

Na legislação penal hodierna isso não ocorre (desde a Reforma de 1984). Agora 0 imputável que praticar conduta definida como crime cumprirá pena e o inimputável sofrerá a medida de segurança. O 'limítrofe' semi-imputável sofrerá ou pena ou medida de segurança, de maneira diametralmente oposta ao que ocorria no sistema duplo binário. 0 atual sistema é denominado vicariante.

Por isso, fica claro que o sistema vicariante atualmente vigente no país é muito mais adequado a lidar com a questão dos inimputáveis e semi-imputáveis do que o anteriormente adotado.

\section{Pressupostos para aplicação da medida de segurança}

Para que uma medida de segurança seja aplicável é necessário o preenchimento de alguns requisitos:

a) prática de um ilícito penal;

b) periculosidade do agente.

É inadmissível a aplicação da medida de segurança para alguém que não cometeu nenhum ilícito penal, por razões óbvias, vez que seria medida de absoluto arbítrio estatal. 
Imagine-se que alguém, sem ter cometido qualquer delito, fique em hospital de custódia, apenas por não ter autodeterminação (COSTA, 2007).

0 pressuposto da periculosidade do agente é presumido quanto aos inimputáveis, sendo que no caso dos semi-imputáveis a prova da periculosidade deve existir, sob pena do agente receber pena ao invés de medida de segurança (JESUS, 2006, p. 547).

0 agente, em razão de sua doença mental, será um risco à ordem social, constituindo sua liberdade perigosa para a segurança da sociedade (COSTA, 2007).

De acordo com o acima apresentado, fica claro que, caso reconhecida qualquer excludente de ilicitude ou absolvido o agente, por qualquer razão que não a imputabilidade, não será possível a aplicação da medida de segurança.

\section{Espécies de medida de segurança}

As medidas de segurança são divididas em dois tipos: a medida de segurança detentiva e a medida de segurança ambulatorial.

Ferrari $(2001$, p. 82) entende que a medida de segurança detentiva é fragmentária e residual, devendo apenas ser aplicada em último caso, qual seja, para os semi-imputáveis ou inimputáveis que cometerem crime apenado com reclusão, sendo facultativa a aplicação nos casos de crimes apenados com detenção.

Em que pese esta espécie de medida de segurança ser mais severa, o Código Penal adotou-a como regra geral.

No que tange à medida de segurança em tratamento ambulatorial, é possível fazer uma comparação desta com a pena restritiva de direitos, sendo a medida de segurança detentiva o 'equivalente', mutatis mutandis à pena privativa de liberdade (REALE JÚNIOR et al, 1985, p. 291).

Deve ficar claro que na hipótese do tratamento ambulatorial imposto inimputável [ou semi-imputável] demonstrar-se insuficiente para a cura do paciente, deverá este regime de medida de segurança ser convertido para o detentivo. 


\section{Os limites da medida de segurança}

Chega-se agora, ao cerne do presente trabalho, onde se analisará os limites, tanto mínimos quanto máximos da medida de segurança.

\section{Princípios penais aplicáveis às medidas de segurança}

Sendo a medida de segurança um instituto de Direito Penal, diversos princípios são a ela aplicáveis como maneira de otimizar sua utilização.

Antes de analisarmos os princípios propriamente ditos, interessa realizar um breve interlúdio sobre o que é princípio, para o Direito. Para isso, empresta-se o significado dado a eles por Robert Alexy (apud SILVA, 2002):

[Robert] Alexy divide as normas jurídicas em duas categorias, as regras e os princípios. Essa divisão não se baseia em critérios como generalidade e especialidade da norma, mas em sua estrutura e forma de aplicação. Regras expressam deveres definitivos e são aplicadas por meio de subsunção. Princípios expressam deveres prima facie, cujo conteúdo definitivo somente é fixado após sopesamento com princípios colidentes. Princípios são, portanto, "normas que obrigam que algo seja realizado na maior medida possível, de acordo com as possibilidades fáticas e jurídicas"; são, por conseguinte, mandamentos de otimização. [grifo do autor].

Com essa definição concorda Humberto Bergmann Ávila (1999). Ou seja, os princípios são utilizados para tornar o ordenamento jurídico uno, como deveria ser, evitando conflitos e colisões normativas.

Para o Direito Penal os princípios não atuam apenas como solucionadores de conflitos normativos, mas sim como garantias do cidadão perante o poder punitivo estatal (BITENCOURT, 2008, p. 10).

\section{Princípio da Legalidade}

Este princípio, no que tange ao crime, às penas e às medidas de segurança, está insculpido tanto na Constituição Federal de $1988^{6}$ como no Código Penal ${ }^{7}$.

\footnotetext{
${ }^{6}$ Artigo 50, caput da Constituição da República Federativa do Brasil.

${ }^{7}$ Art 1 .
}

Revista de Direito Público, LondRINA, V. 6, N. 3, P. 53-77, OUT/DEZ 2011. 
Ferrari aduz que para a medida de segurança atender ao princípio da legalidade, o agente deverá ter cometido uma infração penal punível e a medida de segurança estar prevista anteriormente àquela infração, sob pena de violação à Constituição e ao Código Penal (FERRARI, 2001, p. 92).

Luiz Flávio Gomes (1993) vai além, dizendo que o princípio da legalidade obriga o Estado antecipadamente a tornar pública a exata natureza e duração das sanções penais. Tal posição, muito plausível, será analisada mais adiante.

Princípio da Proporcionalidade

Apesar das bem fundamentadas críticas feitas por Virgílio Afonso e Humberto Ávila à utilização do termo 'princípio da proporcionalidade' para evitar desnecessária digressão e, até por motivo de práxis, continuar-se-á utilizando o termo 'princípio', ao invés de 'regra' ou 'postulado'.

0 citado princípio surge vinculado à ideia de limitação do poder estatal. 0 dever de adoção da proporcionalidade está intrinsecamente ligado à concepção de moderação, prudência, equidade, vedação do excesso, dentre outras. Apesar do mesmo não estar expressamente previsto em nossa Constituição, ele está implícito e decorre do próprio Estado de Direito (ARAÚJO, 2009).

A proporcionalidade atua como uma regra de interpretação e aplicação do direito principalmente de interpretação e aplicação dos direitos fundamentais, empregada especialmente nos casos em que um ato do poder público estatal, destinado a promover a realização de um direito fundamental ou de um interesse coletivo, implica a restrição de outro direito fundamental (SILVA, 2002).

A aplicação do citado princípio é fazer com que nenhuma restrição a direitos fundamentais tome dimensões desproporcionais, desarrazoadas. É, para usar uma expressão consagrada, uma restrição às restrições. Para alcançar esse objetivo, 0 ato estatal deve passar pelos exames da adequação, da necessidade e da proporcionalidade em sentido estrito. Esses três exames são, por isso, considerados como sub-regras da regra da proporcionalidade (SILVA, 2002).

Mais à frente será feita, in loco, aplicação do citado princípio, com fins de verificação da constitucionalidade da duração, sem limites, da medida asseguradora.

Revista de Direito Público, LondRINA, V. 6, N. 3, P. 53-77, OUT/DEZ. 2011. 


\section{Princípio da Igualdade}

Tratamento igual aos iguais e desigual aos desiguais, na medida de suas desigualdades. Este postulado, criado por Aristóteles, ainda é a base da ideia de isonomia, consagrada no artigo 50 da Constituição Federal. Sabendo-se que a diferença é inerente a todos os seres humanos, a promoção da igualdade busca à igualização daqueles menos favorecidos (FERRARI, 2001).

Para Celso Antônio Bandeira de Mello (2010, p. 10), a Lei não pode servir como fonte de privilégios ou perseguições e sim como instrumento regulador da vida em sociedade, devendo tratar equitativamente todos os cidadãos, sendo este o conteúdo político-ideológico do princípio da isonomia, juridicizado na Constituição .

Luiz Flávio Gomes (1993) entende que os submetidos à medida de segurança têm sua igualdade violada em comparação aos apenados comuns, visto que para os primeiros a intervenção estatal é indeterminada, enquanto que para os últimos já existe um limite máximo determinado por lei. Tal diferença de tratamento violaria, a princípio, a igualdade constitucionalmente assegurada.

\section{Limite máximo da medida de segurança}

Chega-se aqui ao ponto nevrálgico do presente estudo, o limite máximo das medidas de segurança. Analisar-se-á por quanto tempo poderá ficar internado um indivíduo sem autodeterminação mental e que cometera um fato típico e punível.

Trata-se de tema tormentoso.

Historicamente, tanto a doutrina como a jurisprudência entendiam, de maneira pacífica, pela duração indeterminada da medida de segurança, perdurando a mesma enquanto não fosse constatada a cessação da periculosidade, através de perícia médicolegal.

Esta, inclusive, pode-se sustentar tranquilamente, é a posição do nosso Código, após a reforma penal de $1984 .^{8}$

\footnotetext{
${ }^{8}$ Conforme se depreende do artigo 97, § 1o - A internação, ou tratamento ambulatorial, será por tempo indeterminado, perdurando enquanto não for averiguada, mediante perícia médica, a cessação de periculosidade. 0 prazo mínimo deverá ser de 1 (um) a 3 (três) anos.

ReVISTA de Direito Público, LondRINA, V. 6, N. 3, P. 53-77, OUT/DEZ. 2011. 
Para fins de ilustração, cita-se a lição dada por Aníbal Bruno (2009, p. 221-222):

As medidas de segurança pessoais, detentivas e não detentivas, são indeterminadas no máximo, mas tem um prazo mínimo de execução fixado na lei, em correspondência com a severidade da pena e, portanto, com a gravidade do crime.

Vencido esse prazo, poderá ser revogada a medida asseguradora. Mas não será pelo decorrer puro e simples do prazo mínimo fixado que ela se revogará. A medida de segurança não se revoga enquanto não cessa o estado perigoso que a determinou.

Decorrido o mínimo estabelecido pela lei para a duração da medida, deverá o juiz proceder a exame minucioso das condições atuais do agente, para chegar a verificar se realmente cessou ou não o seu estado perigoso. Somente se deixou de existir a perigosidade, será a medida revogada.

Esta posição era defendida pelos autores mais tradicionais, como Nélson Hungria, Heleno Fragoso, Damásio de Jesus, dentre outros.

Na mesma corrente dos doutrinadores acima citados, e do Código Penal, o Extinto Tribunal Federal de Recursos posicionava-se?:

Penal - inimputabilidade - medida de segurança - aplicação. 0 inimputável do artigo 26, caput, do c. Penal, deve se submeter-se a medida de segurança prevista no art. 97 do mesmo estatuto, consistente em internação em estabelecimento adequado pelo prazo necessário a sua recuperação. Apelação provida.

Seguindo a mesma linha, o Superior Tribunal de Justiça vem historicamente decidindo da mesma maneira, qual seja, que a medida de segurança não comporta prazo máximo, devendo haver, caso a caso, exame da periculosidade do agente antes deste voltar ao convívio social. Um exemplo disto é o seguinte acórdão ${ }^{10}$ :

HABEAS CORPUS. FURTO TENTADO. PACIENTE INIM PUTÁVEL. SENTENÇA ABSOLUTÓRIA IM PRÓPRIA. IM POSIÇÃO DE M EDIDA DE SEGURANÇA. INTERNAÇÃO. PRAZO INDETERM INADO. CESSAÇÃO DE PERICULOSIDADE. ORDEM DENEGADA. DECRETO № 7.046/09. INDULTO. ORDEM CONCEDIDA DE OFÍCIO.

1. [omissis]

2.[omissis]

\footnotetext{
${ }^{9}$ Apelação Criminal 8430/RJ. Relator Cid Flaquer Scartezzini. Terceira Turma. Julgamento 28 fevereiro 1989. Disponível em: $\measuredangle t t p: / / w w w . s t j . j u s . b r / S C O N / j u r i t f r / d o c . j s p ? l i v r e=m e d i d a+d e+s e g u r a n \% E 7 a \& \& b=T F R C \& p=t r u e$ $\& \mathrm{t}=\& \mid=20 \& \mathrm{i}=1>$. Acesso em: 12 mar 2011.

${ }^{10} \mathrm{HC} 112.227 / R S$. Relator M inistro Jorge Mussi. Quinta Turma. Julgamento em 17 jun 2010. Disponível em: «ttps://ww2.stj.jus.br/ revistaeletronica/Default.asp? registro $=200801680873 \&$ dt_publicacao $=09 / 08 / 2010>$. Acesso em: 1 out 2010.
}

Revista de Direito Público, LondRINA, V. 6, N. 3, P. 53-77, OUT/DEZ. 2011. 
3. Esta Corte Superior firmou entendimento de que a medida de segurança é aplicável ao inimputável e tem prazo indeterminado, perdurando enquanto não for averiguada a cessação da periculosidade (Precedentes STJ).

4. Não se verificando tal condição, não há falar-se em extinção da medida de segurança. Ordem denegada. Habeas Corpus concedido de ofício para extinguir a medida de segurança imposta ao paciente em razão do disposto no art. 10, inciso VIII, do Decreto Presidencial no 7.046/09.

Por conseqüência, se depreende que a corrente mais tradicional entende que 0 agente submetido à medida de segurança deve ficar fora do convívio da sociedade até eventual cura, sem qualquer possibilidade de liberação enquanto 0 agente permanece perigoso.

Contudo, a posição tradicional acima elencada, legalista ao extremo, deixa de atentar aos mandamentos nucleares de nosso sistema jurídico, os princípios.

As disposições da lei penal acerca das medidas de segurança devem ser lidas à luz dos princípios penais, principalmente da igualdade, proporcionalidade e legalidade.

A posição tradicional culmina, por vezes, em casos como o de Febrônio Índio do Brasil, que sujeito à medida de segurança detentiva no Manicômio Judiciário Heitor Carrilho, no Rio de Janeiro, lá permaneceu até seu óbito, por 46 longos anos (COSTA, 2007).

Prosseguindo nesta ideia, o próprio Superior Tribunal de Justiça, dentro de sua Sexta Turma, recentemente decidiu de maneira diferente, entendendo, através da análise dos princípios da isonomia e da proporcionalidade, que o vicariato só poderia ser submetido à medida asseguradora pelo tempo máximo que a lei comina de pena, em abstrato, ao delito a ele imputado:

HABEAS CORPUS. ART. 129, CAPUT, DO CP. EXECUÇÃO PENAL. MEDIDA DE SEGURANÇA. LIMITE DE DURAÇÃO. PENA MÁXIM A COMINADA EM ABSTRATO AO DELITO COMETIDO. PRINCÍPIOSDA ISONOMIA E DA PROPORCIONALIDADE.

1. Prevalece, na Sexta Turma desta Corte, a compreensão de que o tempo de duração da medida de segurança não deve ultrapassar o limite máximo da pena abstratamente cominada ao delito praticado, com fundamento nos princípios da isonomia e da proporcionalidade.

2. No caso, portanto, estando o paciente cumprindo medida de segurança (internação) em hospital de custódia e tratamento pela prática do delito do art. 129, caput, do Código Penal, o prazo prescricional regula-se pela pena em abstrato cominada a cada delito isoladamente.

3. Conforme bem ressaltou o Ministério Público Federal em seu parecer à fl. 112, "in casu, o paciente se encontra submetido a medida de segurança há mais de 16 (dezesseis) anos, quando a pena máxima abstratamente cominada ao delito que se

Revista de Direito Público, LondRINA, V. 6, N. 3, P. 53-77, OUT/DEZ. 2011. 
Ihe atribui é de 2 anos. Vai de encontro ao princípio da razoabilidade manter 0 paciente privado de sua liberdade por tão extenso período pela prática de delitos de menor potencial ofensivo, máxime quando possui condições de continuar sendo tratado por pessoa de sua família, com recursos médicos-psiquiátricos oferecidos pelo Estado." 4. 0 delito do art. 129, caput do Código Penal prevê uma pena de 3 (três) meses a 1 (um) ano de detenção. Isso significa que a medida de segurança não poderia, portanto, ter duração superior a 4 (quatro) anos, segundo art. 109, V, do CP. Em outras palavras, tendo o paciente sido internado no Instituto Psiquiátrico Forense em 30/10/1992, não deveria o paciente lá permanecer após 30/10/1996.

5. Ordem concedida a fim de declarar extinta a medida de segurança aplicada em desfavor do paciente, em razão do seu integral cumprimento. ${ }^{11}$

Vinícius de Toledo Piza Peluso também entende da mesma maneira que a Sexta Turma do Superior Tribunal de Justiça, asseverando que o limite máximo de execução da medida de segurança de internamento deve corresponder ao máximo da pena abstratamente cominada ao delito que a embasou (PELUSO, 2009).

Cezar Bitencourt (2008, p. 327), Luiz Flávio Gomes (1993) e Janora Rossetti (1992) coadunam do mesmo entendimento, criticando o posicionamento daqueles que dizem que 0 prazo é indeterminado. Entende da mesma maneira Juarez Cirino, asseverando, de maneira incisiva, que a melhor opção seria mesmo a de que o limite máximo da medida de segurança deva coincidir com a pena criminal aplicável no caso concreto se 0 autor fosse inimputável (SANTOS, 2009, p. 666), posição esta coadunada pelo desembargador do Tribunal de Justiça do Rio Grande do Sul, Amilton Bueno de Carvalho ${ }^{12}$.

o Supremo Tribunal Federal posiciona-se de maneira oblíqua à posição tradicionalista, entendendo que a medida de segurança não pode superar ao prazo máximo de pena no Brasil, que é de 30 anos, como se về ${ }^{13}$ :

PENAL EXECUÇÃO PENAL. HABEAS CORPUS. RÉU INIMPUTÁVEL. MEDIDA DE SEGURANÇA. PRESCRIÇÃO. INOCORRÊNCIA. EXTINÇÃO DA M EDIDA, TODAVIA, NOS TERMOS DO ART. 75 DO CP. PERICULOSIDADE DO PACIENTE SUBSISTENTE. TRANSFERÊNCIA PARA HOSPITAL PSIQUIÁTRICO, NOS TERMOS DA LEI 10.261/01. WRIT CONCEDIDO EM PARTE. I - Não há falar em extinção da punibilidade pela prescrição da medida de segurança uma vez que a internação do paciente

\footnotetext{
${ }^{11}$ HC 143.315/RS. Relator Ministro Og Fernandes. Sexta Turma. Julgado em 05 ago 2010. Disponível em: $\varangle$ ttps:// ww2.stj.jus.br/ revistaeletronica/Default.asp? registro $=200901458955 \& d t$ publicacao $=3 / 08 / 2010>$. Acesso em: 2 out 2010.

${ }^{12}$ TJRS, Apelação Crime 70010817724/2005. Relator Amilton Bueno de Carvalho. 5a Câmara Criminal. Julgamento 31 jan 2005. HC 98360/RS, Relator Ministro Ricardo Lewandowski. Primeira Turma. Julgado em 04 ago 2009. Disponível em: বttp://redir.stf.jus.br/paginador/paginador.jsp?docTP=AC\&doclD=604609>. Acesso em: 3 out 2010.
}

ReVISTA de Direito Púbuico, LondRINA, V. 6, N. 3, P. 53-77, OUT/DEZ. 2011. 
interrompeu o curso do prazo prescricional (art. 117, V, do Código Penal). II - Esta Corte, todavia, já firmou entendimento no sentido de que o prazo máximo de duração da medida de segurança é o previsto no art. 75 do CP, ou seja, trinta anos. Precedente. III - Laudo psicológico que, no entanto, reconheceu a permanência da periculosidade do paciente, embora atenuada, o que torna cabível, no caso, a imposição de medida terapêutica em hospital psiquiátrico próprio. IV - Ordem concedida em parte para extinguir a medida de segurança, determinando-se a transferência do paciente para hospital psiquiátrico que disponha de estrutura adequada ao seu tratamento, nos termos da Lei 10.261/01, sob a supervisão do M inistério Público e do órgão judicial competente.

Com efeito, existem posições em muito dissonantes entre si, cada uma com uma base jurídica diferente. Para deslindar este conflito deve-se aprofundar o estudo dos princípios.

Sistematização e ponderação dos princípios

Deve-se refletir, na esteira das posições mais modernas, sobre o seguinte: como aplicar os princípios para 'otimizar' a norma jurídica prevista no artigo 91, § 1ำ do Código Penal.

Primeiro, deve-se exaltar a evolução, tanto doutrinária, como jurisprudencial sobre a duração das medidas de segurança. Contudo, tanto os Tribunais como os autores acima citados, apesar de na maioria das vezes chegarem a soluções satisfatórias, partem de premissas equivocadas. Nas soluções a que chegam, muitas vezes se utilizam dos princípios de maneira indiscriminada, sem qualquer sistematização.

O Direito, como toda ciência, impõe ao intérprete que crie uma concatenação lógica de ilações, para chegada a uma conclusão. Na ciência filosófica, o exemplo mais famoso foi o de Renè Descartes, com o seu famoso: "penso, logo, existo". Na física e na matemática, iniciam-se complexas fórmulas a partir de dezenas de ilações, na maioria delas de simplicidade frugal.

Por isso, aqui se deseja utilizar uma sistematização acerca da duração das medidas de segurança, de maneira que o leitor, posteriormente, seja em sua vida acadêmica, seja na profissional, possa se utilizar das formulações para chegar a uma solução otimizada pelos princípios.

ReVISTA de Direito Púbuico, LondRINA, V. 6, N. 3, P. 53-77, OUT/DEZ. 2011. 
Aplicação dos Princípios da Legalidade e da Igualdade

Primeiro, a aplicação do princípio da legalidade. A leitura tradicional do mesmo denota que todas as punições passíveis de realização pelo Estado devem estar previamente cominadas, nullum crimen, nulla poena sine praevia lege. Contudo, normalmente as medidas de segurança vem sendo aplicadas conforme a legislação, sem qualquer limite máximo, devendo a aferição da periculosidade determinar o período da soltura.

Entende-se, à luz do princípio da legalidade constitucionalmente previsto, que 0 vicariato deve saber, de antemão, o máximo de tempo possível que poderá ficar submetido a tratamento.

Veja-se que isso exige um outro questionamento, acerca da maneira de se possibilitar àquele que recebeu a decisão absolutória imprópria um meio de saber quanto tempo ficará sob tutela estatal.

Neste diapasão, uma solução plausível seria que o Magistrado, ao absolver impropriamente 0 agente, realize uma dosimetria da pena 'ficta', de forma que o vicariato saiba, desde então, qual o máximo de tempo que ficará com sua liberdade restrita.

Por decorrência da natureza das medidas de segurança, caso o inimputável cure-se de sua doença mental antes do advento do prazo máximo, ele deverá ser liberado, visto que não mais subsiste o mal que Ihe retirava sua autodeterminação.

Dessa dosimetria ficta, realizada no bojo da sentença, também há a promoção do princípio da igualdade. Isso porque se evita o que é um problema sério na aplicação das medidas de segurança, a desigualdade de tratamento aos vicariatos, em comparação com os apenados comuns.

A título de exemplo, imagine-se um imputável ' $A$ ', condenado pelo crime de homicídio qualificado, poderá receber pena variável de 12 a 30 anos.

Suponha-se que este condenado ' $A$ ' receba a pena de 14 anos de reclusão, a serem inicialmente cumpridos em regime fechado. Agora, imagine-se um inimputável ' $B$ ' que, sem autodeterminação [a título de conjectura, um toxicômano absolutamente incapaz], em uma discussão familiar [ou seja, por motivo fútil], assassine um familiar. Segundo tanto a corrente do Supremo Tribunal Federal, como a corrente de Luiz Flávio Gomes, o inimputável receberá

Revista de Direito Público, LondRINA, V. 6, N. 3, P. 53-77, OUT/DEZ. 2011. 
a medida de segurança detentiva pelo prazo de 30 anos, se antes não se recuperar de sua doença mental.

Ou seja, um homicida comum, culpável, que assassinou em pleno domínio de suas faculdades, ficará segregado por bem menos tempo do que um homicida doente mental. Isso não é isonômico. Por casos como este, que é necessário que o magistrado realize uma dosimetria ficta, quando da sentença absolutória imprópria, com fins de que seja dado tratamento isonômico ao vicariato em comparação ao apenado comum.

\section{Aplicação do Princípio da Proporcionalidade}

Para fins ilustrativos e práticos, para que o leitor possa realizar em seu ambiente forense entendimento similar, emprega-se um caso concreto para aplicação do princípio da proporcionalidade.

Vez que foi anteriormente citado neste trabalho, utilizar-se-á, como parâmetro o caso de Febrônio Índio do Brasil.

Em breve escorço, se tem que Febrônio tinha ilusões de ser um enviado de Deus à Terra para proclamar que este último ainda estava vivo. Munido dessas ilusões, Febrônio, que se intitulava 'Filho da Luz', durante os anos 20, acabou por cometer cinco homicídios, quatro estupros, entre inúmeras outras transgressões penais. Ele, após rumoroso julgamento, acabou sendo absolvido impropriamente, recebendo medida de segurança. Mais de 40 anos depois, acabou falecendo em razão de um enfisema pulmonar. Frise-se que o mesmo ainda estava internado em manicômio judiciário quando da sua morte (CASOY, 2004).

Diante deste caso, o papel que se presta aqui é verificar, se à luz do princípio da proporcionalidade a atuação jurídica estatal neste caso foi a mais correta.

Sabe-se que, de acordo com o regramento de Robert Alexy, a proporcionalidade é dividida em três subrregras, devendo o intérprete utilizá-las em ordem, a fim de verificar se, no caso concreto, aquela violação jurídica é proporcional. 
Aplicação da sub-regra da adequação

Primeiro analisar-se-á se a medida aplicada a Febrônio foi adequada. Para que seja adequado, o objetivo legítimo pretendido deve ser alcançado ou pelo menos fomentado (SILVA, 2002). No caso, deve-se perscrutar se a internação de Febrônio em um manicômio judiciário alcança o fim pretendido, qual seja, retirar o doente mental 'perigoso' do meio social. A priori, sim. E o fim mediato pretendido, a 'cura' do paciente, pode ser fomentada através da internação? Em princípio, também se entende que sim.

Claro está que esta análise faz-se meramente em tese, visto que não temos acesso [e nem é esse o foco do presente estudo] às condições médicas dos manicômios judiciários da época.

Portanto, infere-se que a internação de Febrônio em manicômio judiciário alcança os objetivos pretendidos, qual sejam, a proteção da sociedade e a busca da cura do vicariato, sendo adequada, nos termos da primeira subrregra da proporcionalidade.

\section{Aplicação da sub-regra da necessidade}

0 ato estatal que limita um direito fundamental é somente necessário caso a realização do objetivo perseguido não possa ser promovida com a mesma intensidade por meio de outro ato que limite, em menor medida, o direito fundamental atingido (SILVA, 2002).

Pois bem, como visto no trabalho de Virgilio Afonso da Silva, o exame da necessidade é um exame comparativo, ou seja, analisa-se a possibilidade de outra medida ter o mesmo efeito da analisada. No caso de Febrônio, existiria outra medida estatal que pudesse tanto fomentar sua cura terapêutica como afastá-lo do meio social?

Muito provavelmente, a resposta é não. 0 mero tratamento ambulatorial dificilmente seria capaz de conter pessoa com tamanha potencialidade lesiva.

Por conseqüência, denota-se que o único meio possível de se chegar ao objeto adequado, com menor lesão ao direito fundamental à segurança pública coletiva e menor lesão à sanidade mental do paciente é a internação em manicômio judiciário, vez que a submissão a tratamento ambulatorial não seria adequada à segurança pública e a aplicação 
de pena privativa de liberdade não seria adequada à promoção da cura terapêutica de Febrônio.

Aplicação da sub-regra da proporcionalidade em sentido estrito.

A proporcionalidade em sentido estrito é o terceiro exame dentro do princípio da proporcionalidade, que concerne em um sopesamento entre a intensidade da restrição ao direito fundamental atingido e a importância da realização do direito fundamental que com ele colide e que fundamenta a adoção da medida restritiva.

Por conseguinte, na análise presentemente realizada deve ser questionado se a proteção ao meio social justificaria a segregação indeterminada de Febrônio. A resposta é a parte mais 'discricionária' da análise da proporcionalidade.

Poderia parecer simples a resposta, ao se dizer que a proteção social, por ser mais importante que a 'liberdade' de Febrônio, deveria afastar o direito deste viver em sociedade. Todavia, a proporcionalidade em sentido estrito deve ser utilizada como um meio de verificação de possível excesso estatal (ÁVILA, 1999).

Portanto, a única resposta possível é que a medida [segregação do inimputável indeterminadamente] é desproporcional, visto que como em relação a nenhum outro indivíduo há permissão legal para restrição da liberdade por mais de 30 (trinta) anos, haveria um excesso injustificável por parte do Estado.

Desta maneira, sistematizado o porquê das medidas de segurança terem um limite máximo de 30 anos, como as penas privativas de liberdade

O problema da manutenção da periculosidade após o decurso do prazo

A opção pela tese da limitação do tempo máximo da medida de segurança leva a outro questionamento. 0 que fazer com aqueles doentes mentais que ainda remanescem perigosos?

Revista de Direito Público, LondRINA, V. 6, N. 3, P. 53-77, OUT/DEZ. 2011. 
0 Direito Português prevê uma prorrogação por prazo de 02 (dois) anos, com possibilidade de renovação, caso o inimputável permaneça perigoso (DIAS, 2001, p. 122). ${ }^{14}$ Esta opção legislativa, pelo menos para o ordenamento jurídico brasileiro, parece violar a proporcionalidade, como visto acima.

A primeira opção seria a simples liberação do paciente, independente da sua periculosidade. Tal opção não é atraente, por razões óbvias.

A solução tende a ser como a apresentada por Reale Ferrari (2001, p. 193-194). A solução proposta consiste no Ministério Público, antes do término da medida de segurança, notando a altíssima periculosidade do vicariato, requerer sua interdição civil ${ }^{15}$.

Claro está também que a interdição civil não poderá ser usada, de maneira indiscriminada, como meio de restrição de liberdade de todo e qualquer inimputável, devendo haver cautela na sua utilização, tanto pelo Ministério Público, como pelo Poder Judiciário.

\section{Conclusão}

Diante da abordagem realizada, infere-se que o sistema de sanções penais passou por grandes mudanças desde seu início, passando de um sistema monista, com a única sanção sendo a pena privativa de liberdade, para o atual sistema dualista, com a previsão também da medida de segurança para aqueles que, por doença mental, não tem poder de autodeterminação.

Viu-se que a medida de segurança tem como objeto imediato a busca da cura do inimputável, sendo que a restrição de sua liberdade de locomoção decorre do agente ter se mostrado perigoso ao cometer um ilícito penal. Ademais, observou que, de todo caso, para

\footnotetext{
${ }^{14}$ Art. 92 , § 3o - Se o facto praticado pelo inimputável corresponder a crime punível com pena superior a 8 anos e o perigo de novos factos da mesma espécie for de tal modo grave que desaconselhe a libertação, 0 internamento pode ser prorrogado por períodos sucessivos de 2 anos até se verificar a situação prevista no no 1.

${ }^{15}$ Nascerá daí uma questão: acerca dos direitos dos civilmente internados. A Lei 10.216/2011 disciplinou 0 tema e trata acerca da internação compulsória e voluntária. No caso da internação compulsória, a Lei determina que o Ministério Público seja cientificado, o que vai de encontro ao proposto aqui, visto que sustentou-se acima que o Ministério Público deveria requerer a internação. Para maiores detalhes sobre a temática conferir: Britto (2004). Correia, Lima e Alves (2007). Não se aprofunda aqui no tema por razões de espaço e porque isso exigiria outro recorte temático, um com a relação entre direito penal, criminologia e saúde pública.
}

Revista de Direito Público, LondRINA, V. 6, N. 3, P. 53-77, OUT/DEZ 2011. 
uma possível submissão do agente a uma medida de segurança é imperioso que o mesmo tenha cometido um ilícito penal, sendo impossível atualmente a sua segregação apenas em decorrência de uma periculosidade abstrata.

Em seguida, apurou-se que a medida de segurança tem duas espécies, uma mais restritiva, que é a de internação, outra menos restritiva, que é a de tratamento ambulatorial.

Mais à frente, passou-se a um estudo dos limites da medida de segurança, em especial o limite máximo. Observou-se que os princípios do direito penal servem como balizadores à atividade estatal e jurisdicional, servindo como parâmetros à aplicação das medidas de segurança.

Anotaram-se as diferentes posições, tanto dos tribunais, como dos autores, acerca do limite máximo da medida de segurança. Em seguida, fez-se breve análise acerca destas posições para posterior utilização das mesmas como início de uma análise sistemática acerca do limite máximo das medidas de segurança.

Após aplicação concreta dos princípios chegou-se a algumas soluções, quais sejam:

1. Para não violação dos princípios da legalidade e da isonomia, o Juiz, quando da aplicação de medida absolutória imprópria, deve perfazer uma dosimetria 'ficta' da pena, com fins de o inimputável ter prévio conhecimento do tempo que ficará internado ou submetido a tratamento, evitando-se tratamento desigual deste em relação ao imputável.

2. A proporcionalidade não permite que os vicariatos sejam submetidos à medida de segurança por tempo indeterminado, mesmo com remanescência da periculosidade, devendo, em todo caso, a permanência destes, sob custódia do Estado, ter como baliza máxima o prazo de 30 anos.

3. No caso de submetidos à medida asseguradora que permaneçam perigosos quando findo o prazo, poderá o Ministério Público requerer a interdição dos mesmos, nos termos do Código Civil vigente.

4. A interdição civil do vicariato deve ser usada com parcimônia, sob pena de ferimento ao princípio da proporcionalidade.

\section{Referências}

ReVISTA de Direito Público, LondRINA, V. 6, N. 3, P. 53-77, OUT/DEZ. 2011. 
ARAÚJO, Fábio Roque da Silva. O Principio da Proporcionalidade Aplicado ao Direito Penal: Fundamentação Constitucional da Legitimidade e Limitação do Poder de Punir. Revista da Escola da Magistratura do Estado do Rio de Janeiro, v. 12, n, 45, p. 273-315, 2009.

AVILA, Humberto Bergmann. A distinção entre princípios e regras e a redefinição do dever de proporcionalidade. Revista de Direito Administrativo, Rio de Janeiro, v. 215, p. 151-179, 1999.

BECCARIA, Cesare. Dos Delitos e das Penas. São Paulo: Cid, 2002.

BITENCOURT, Cezar Roberto. Tratado de Direito Penal. Parte Geral. 12.ed. São Paulo: Saraiva, 2008.

BRITTO, Renata Côrrea. A Internação Psiquiátrica Involuntária e a Lei 10.216/01 - Reflexões acerca da garantia de proteção aos direitos da pessoa com transtorno menta. 2004.

Dissertação (Mestrado em Saúde Pública) - Escola de Saúde Pública - Fundação Oswaldo Cruz - Rio de Janeiro, 2004. Disponível em: «ttp://thesis.icict.fiocruz.br/pdf/brittorcm.pdf>. Acesso em: 10 out. 2011.

BRUNO, Aníbal. Direito Penal - Parte Geral - Pena e Medida de Segurança. Rio de Janeiro: Forense, 2009.

CALDEIRA, Felipe Machado. Evolução Histórica, Filosófica e Teórica da Pena. Revista da Escola da M agistratura do Estado do Rio de Janeiro, v. 12, n. 45, p. 255-272, 2009.

CASOY, Ilana. Serial killers: made in Brasil. 2. ed. São Paulo: Arx, 2004.

CORREIA, Ludmila Cerqueira; LIM A, Isabel M aria Sampaio Oliveira; ALVES, Vânia Sampaio. Direitos das pessoas com transtorno mental autoras de delitos. Cadernos de Saúde Pública, v. 23, n.9, p.1995-2002, Set., 2007.

COSTA, Álvaro Mayrink. Medidas de Segurança. Revista da Escola da Magistratura do Estado do Rio de Janeiro, Rio de Janeiro, v. 10, n. 37, p. 17-40, 2007.

DIAS, Jorge de Figueiredo. Temas Básicos da Doutrina Penal. Coimbra: Coimbra Editora, 2001.

D'URSO, Luiz Flávio Borges. M edidas de Segurança no Direito Comparado. Revista Brasileira de Ciências Criminais, São Paulo, ano 1, v. 3, p. 113-118, jul./set., 1993.

FERRARI, Eduardo Reale. M edidas de Segurança e Direito Penal no Estado Democrático de Direito. São Paulo: Revista dos Tribunais, 2001. 
FRAGOSO, Heleno Cláudio. Lições de Direito Penal: parte geral. 8. ed. Rio de Janeiro: Forense, 1985.

. Sistema do duplo binário: vida e morte. Studi in M emoria di Giacomo Delitala. vol. III. Giùffre, 1984. p. 1907-1930. Disponível em: «www.fragoso.com.br/cgi-bin/heleno_ artigos/arquivo 19.pdfacess. Acesso em: 19 fev. 2011.

GOM ES, Luiz Flávio. M edidas de Segurança e Seus Limites. Revista Brasileira de Ciências Criminais. São Paulo, p. 64-72, abr-jun, 1993.

JESUS, Damásio E. de. Direito Penal - Parte Geral. São Paulo: Saraiva, 2006. v. 1.

M ELLO, Celso Antônio Bandeira de. Conteúdo Jurídico do Princípio da Igualdade. 2. ed. São Paulo: M alheiros, 2010.

PANCHERI, Ivanira. M edidas de Segurança. Revista Brasileira de Ciências Criminais, São Paulo, ano 5, n. 20, p. 105-112, out./dez., 1997.

PELUSO, Vinícius de Toledo Piza. A medida de segurança de internamento para inimputáveis e seu prazo máximo de execução. São Paulo: Juspodivm, 2009.

REALE, M iguel. Lições preliminares de Direito. São Paulo: Saraiva, 2005.

REALE JÚNIOR, Miguel et al. Penas e M edidas de Segurança no Novo Código. Rio de Janeiro: Forense, 1985.

RIBEIRO, Bruno de Morais. M edidas de Segurança. Porto Alegre: Sergio Antonio Fabris, 1998.

ROSSETTI, Janora Rocha. Da Prescrição das M edidas de Segurança. Revista dos Tribunais, São Paulo, v. 679, ano 81, p. 301-307, maio, 1992.

SANTOS, Marino Barbero. As M edidas de Segurança na Legislação Espanhola. Revista Brasileira de Ciências Criminais. São Paulo, ano 3, v. 9, p. 33-39, jan./mar, 1995.

SANTOS, Juarez Cirino dos. Direito Penal. Rio de Janeiro: Lúmen Júris, 2009. v. 1.

SILVA, Luis Virgílio Afonso da. O Proporcional e o Razoável. Revista dos Tribunais, São Paulo, ano 91, n. 798, p. 23-50, 2002. 
Artigo recebido em:

19 mar. 2011

Artigo aprovado em:

03 nov. 2011 